\title{
Letter
}

\section{Spiro-Configured Bifluorenes: Highly Efficient Emitter for UV Organic Light-Emitting Device and Host Material for Red Electrophosphorescence}

Ken-Tsung Wong, Yuan-Li Liao, Yu-Ting Lin, Hai-Ching Su, and Chung-chih Wu

Org. Lett., 2005, 7 (23), 5131-5134• DOI: 10.1021/ol051865q • Publication Date (Web): 13 October 2005

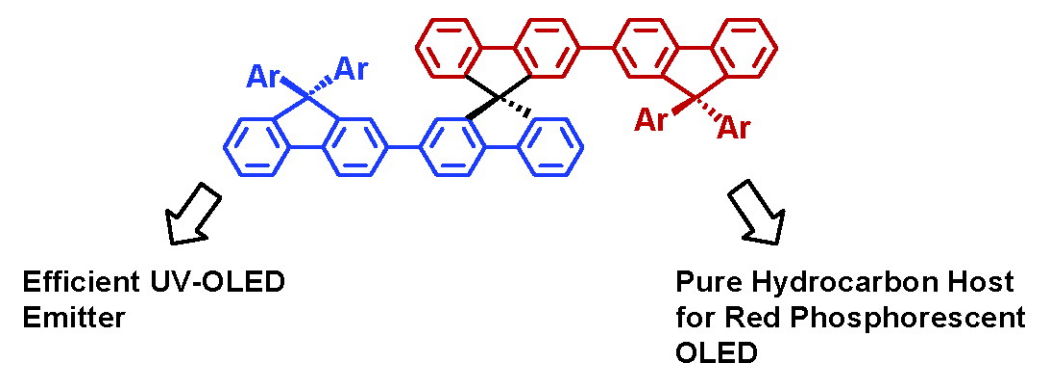

\section{More About This Article}

Additional resources and features associated with this article are available within the HTML version:

- Supporting Information

- Links to the 12 articles that cite this article, as of the time of this article download

- Access to high resolution figures

- $\quad$ Links to articles and content related to this article

- $\quad$ Copyright permission to reproduce figures and/or text from this article

\section{View the Full Text HTML}




\section{Spiro-Configured Bifluorenes: Highly Efficient Emitter for UV Organic}

\author{
Ken-Tsung Wong, ${ }^{, \dagger}$ Yuan-Li Liao, ${ }^{\dagger}$ Yu-Ting Lin, ${ }^{\ddagger}$ Hai-Ching Su, ${ }^{\ddagger}$ and
} Chung-chih Wu $\mathbf{u}^{*, \neq}$

Department of Chemistry and Department of Electrical Engineering, Graduate Institute of Electro-optical Engineering and Graduate Institute of Electronics Engineering, National Taiwan University, Taipei 106, Taiwan

kenwong@ntu.edu.tw

Received August 4, 2005

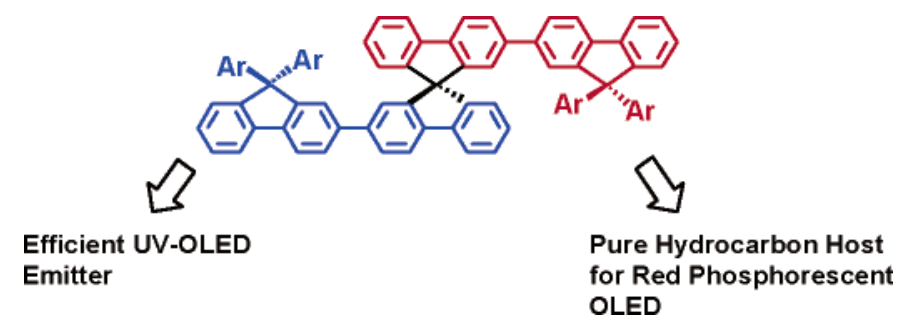

Remarkable UV OLED devices using novel spiro-configured bifluorenes as UV emitters have been successfully achieved with external quantum efficiencies up to $2.6-3.1 \%$ and emission wavelengths as short as $370 \mathrm{~nm}$. In addition, these large-gap materials have been shown to be effective hosts for red phosphorescent emitters in phosphorescent OLEDs. This result represents the first example that pure hydrocarbon molecules can serve as an efficient host for red electrophosphorescence devices.

Organic materials with large energy gaps are of increasing importance due to rapid development of organic optoelectronic devices. For instance, although the emission wavelengths of organic light-emitting devices (OLEDs) have covered almost the whole visible range, extending OLED emission into the true ultraviolet (UV) wavelength is still challenging. In addition, the development of highly efficient phosphorescent OLEDs requires wide-gap materials as effective host materials for triplet dopant emitters. Existing wide-gap materials used for UV OLEDs or hosts of phosphorescent OLEDs are mainly limited to a few functionalized structural features, such as materials containing arylamines, mainly carbazoles, ${ }^{1}$ and silane moieties. ${ }^{2}$ Up to date, pure hydrocarbons of low molecular weight have rarely been successful in these aspects and purposes.

\footnotetext{
† Department of Chemistry.

$\doteqdot$ Department of Electrical Engineering.
}

In searching for large-gap hydrocarbons for optoelectronic applications, oligofluorenes may be considered as promising candidates since they show efficient emission at short wavelengths, reversible and stable electrochemical properties in both oxidation and reduction, ${ }^{3}$ and intriguing bipolar

(1) (a) Baldo, M. A.; Lamansky, S.; Burrows, P. E.; Thompson, M. E.; Forrest, S. R. Appl. Phys. Lett. 1999, 75, 4. (b) Holmes, R. J.; Forrest, S. R.; Tung, Y.-J.; Kwong, R. C.; Brown, J. J.; Garon, S.; Thompson, M. E. Appl. Phys. Lett. 2003, 82, 2422. (c) Tokito, S.; Iijima, T.; Tsuzuki, T.; Sato, F. Appl. Phys. Lett. 2003, 83, 2459. (d) Yeh, S.-J.; Wu, M.-F.; Chen, C.-T.; Song, Y.-H.; Chi, Y.; Ho, M.-H.; Hsu, S.-F.; Chen, C. H. Adv. Mater. 2005, 17, 285.

(2) (a) Holmes, R. J.; D’Andrade, B. W.; Forrest, S. R.; Ren, X.; Li, J.; Thompson, M. E. Appl. Phys. Lett. 2003, 83, 3818. (b) Ren, X.; Li, J.; Holmes, R. J.; Djurovich, P. I.; Forrest, S. R.; Thompson, M. E. Chem. Mater. 2004, 16, 4734

(3) (a) Wong, K.-T.; Chien, Y.-Y.; Chen, R.-T.; Wang, C.-F.; Lin, Y.T.; Chiang, H.-H.; Hsieh, P.-Y.; Wu, C.-C.; Chou, C. H.; Su, Y. O.; Lee, G.-H.; Peng, S.-M. J. Am. Chem. Soc. 2002, 124, 11576. (b) Wu, C.-C.; Lin, Y.-T.; Wong, K.-T.; Chen, R.-T.; Chien, Y.-Y. Adv. Mater. 2004, 16, 61. 
Table 1. Comparison of Physical Properties of Spiro-Configured Bifluorenes SSS and TST with the Model Bifluorenes B2 and T2

\begin{tabular}{lcccccccc}
\hline compd & $E_{1 / 2 \text { red }^{a}}$ & $E_{1 / 2 \text { oxd }}{ }^{a}$ & $T_{\mathrm{g}}\left({ }^{\circ} \mathrm{C}\right)$ & $T_{\mathrm{d}}\left({ }^{\circ} \mathrm{C}\right)$ & $\mathrm{Abs} \lambda_{\max }(\mathrm{nm}) \mathrm{sol}^{b} / \mathrm{film}$ & $\mathrm{PL} \lambda_{\max }(\mathrm{nm}) \mathrm{sol} b /$ film & $\mathrm{QY}(\mathrm{film})^{c} \%$ & $\mathrm{Phos} \lambda_{\max }(\mathrm{nm})^{d}(\mathrm{eV})$ \\
\hline SSS & -2.72 & 0.92 & 228 & 464 & $310,333 / 312,335$ & $367,387 / 374,392$ & 56 & $545(2.28)$ \\
TST & -2.71 & 0.93 & 197 & 475 & $333 / 333$ & $370,387 / 375,393$ & 60 & $545(2.28)$ \\
B2 & -2.75 & 0.96 & 174 & 367 & $310,333 / 312,335$ & $367,387 / 374,392$ & 66 & $540(2.3)$ \\
T2 & -2.71 & 0.94 & 153 & 369 & $333 / 333$ & $370,387 / 375,393$ & 63 & $540(2.3)$
\end{tabular}

${ }^{a}$ Potentials were recorded relative to ferrocene/ferrocenium $\left(\mathrm{Fc} / \mathrm{Fc}^{+}\right)$oxidation couple. ${ }^{b}$ Measured in $\mathrm{CHCl}_{3}$ soultion. ${ }^{c}$ Measured by calibrated integrating sphere system. ${ }^{d}$ Measured in thin films at $77 \mathrm{~K}$.

charge-transport properties. ${ }^{4}$ By shortening the backbone of oligofluorenes, it is possible to reduce the extent of conjugation and obtain true UV emission below $400 \mathrm{~nm}$. The reduced molecular size, however, renders it difficult for the molecules to acquire the morphological stability that is necessary for forming morphologically stable and uniform amorphous thin films, an essential requirement for OLED applications.

Previously, we have reported that by introducing aryl substitutions through $\mathrm{C} 9$ of fluorenes, one achieves a series of large-gap and efficient UV-emitting bi(9,9-diarylfluorene)s (e.g., B2 and T2 in Scheme 1) with reasonable morphological

Scheme 1. Synthesis of 9,9'-Spirobifluorene Configured Bifluorenes SSS and TST and Structures of Their Single Bifluorene B2 and T2

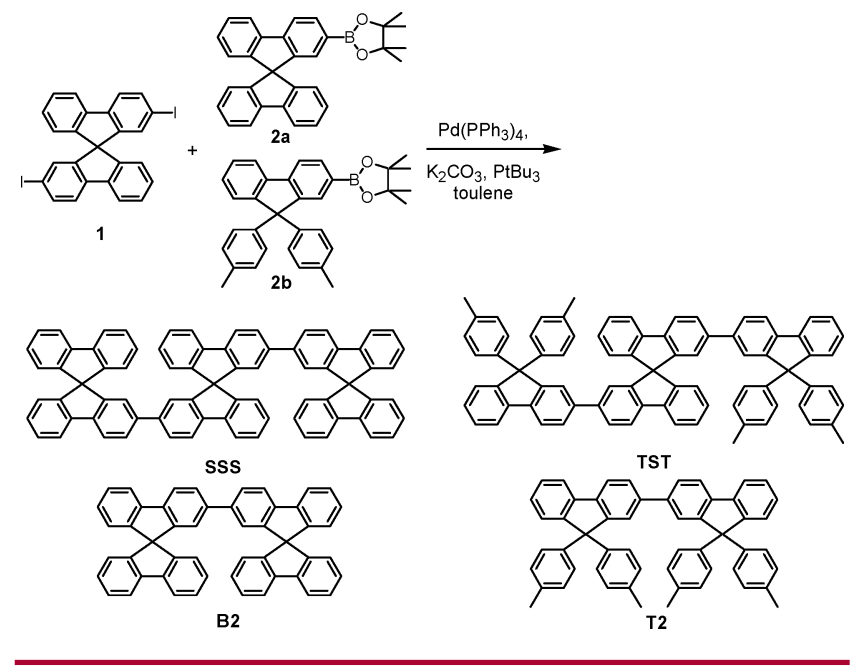

stability. ${ }^{5}$ In this paper, we further report the synthesis and properties of novel 9,9'-spirobifluorene-bridged bi(9,9-diarylfluorene)s and the applications of these large-gap materials in UV and phosphorescent OLEDs. The molecular designs adopted in this communication preserve short $\pi$-conjugation of bifluorenes, which plays a prominent role in the electronic, electrochemical, and photophysical properties of the molecules, and yet the introduction of spiro-configuration gives

(4) (a) Wu, C.-C.; Liu, T.-L.; Lin, Y.-T.; Hung, W.-Y.; Wong, K.-T.; Chao, T.-C.; Hung, T.-S.; Chen, Y.-M. Appl. Phys. Lett. 2004, 85, 1173. (b) Wu, C.-C.; Liu, T.-L.; Hung, W.-Y.; Lin, Y.-T.; Wong, K.-T.; Chen, R.-T.; Chen, Y.-M.; Chien, Y.-Y. J. Am. Chem. Soc. 2003, 125, 3710.

(5) Chao, T.-C.; Lin, Y.-T.; Yang, C.-Y.; Hung, T. S.; Chou, H.-C.; Wu, C.-c.; Wong, K.-T. Adv. Mater. 2005, 17, 992. the molecules a steric and bulky structure that further enhances thermal and morphological stabilities and retains high photoluminescent quantum yields of bifluorenes. In addition to their use in making efficient UV OLEDs, these compounds have also been shown to be effective host materials for Ir-based red-emitting triplet emitters, giving highly efficient red phosphorescent devices. Such a result represents the first example of using the pure hydrocarbon small molecule as an efficient host for red electrophosphorescent devices.

The synthesis of novel 9,9'-spirobifluorene-bridged bi(9,9diarylfluorene)s is depicted in Scheme 1. Suzuki-Miyaura coupling reactions of 2,2'-diiodo-9, $9^{\prime}$-spirobifluorene $(\mathbf{1})^{6}$ with 2-pinacolato boronic ester-9, $9^{\prime}$-spirobifluorenes (2a) and 2-pinacolato boronic ester-9,9-ditolylbifluorene (2b) in the presence of a catalytic amount of $\mathrm{Pd}\left(\mathrm{PPh}_{3}\right)_{4}$ and cocatalyst, $\mathrm{P}^{t} \mathrm{Bu}_{3}$, afforded the titled compounds SSS and TST with isolated yields of $87 \%$ and $83 \%$, respectively.

Cyclic voltammetry was conducted to characterize electrochemical properties of SSS and TST. Both compounds exhibit reversible redox behaviors upon electrochemical oxidation and reduction (Table 1 and Figure S-1, Supporting Information). Both reduction and oxidation potentials of SSS and TST are comparable to those of model compounds B2 and $\mathbf{T} 2$, indicating that the redox properties of the spiroconfigured compounds can be unambiguously ascribed to reduction and oxidation occurring on the individual bifluorene backbone. The spiro-configuration thus produces insignificant perturbation on the properties of molecular orbitals of each bifluorene branch.

Linking two bifluorene moieties through spiro-configuration is significantly beneficial to the thermal stability and morphological stability (Table 1). Thermogravimetric analysis (TGA) indicates that spiro-bridged bifluorenes SSS and TST exhibit decomposing temperatures $\left(T_{\mathrm{d}}\right)$ (corresponding to $10 \%$ weight loss) as high as 464 and $475^{\circ} \mathrm{C}$, respectively, which are almost $100{ }^{\circ} \mathrm{C}$ higher than those of model compounds B2 and T2. In differential scanning calorimetry (DSC), SSS and TST exhibit extinct $T_{\mathrm{g}}$ 's up to 228 and 197 ${ }^{\circ} \mathrm{C}$, respectively, which are more than $44{ }^{\circ} \mathrm{C}$ higher than their corresponding model compounds.

Table 1 also summarizes the photophysical properties of spiro-configured bifluorenes SSS and TST. Spiro-bridged

(6) Wong, K.-T.; Liao, Y.-L.; Peng, Y.-C.; Wang, C.-C.; Lin, S.-Y.; Yang, C.-H.; Tseng, S.-M.; Lee, G.-H.; Peng, S.-M. Cryst. Growth Des. 2005, 5, 667 . 
bifluorenes exhibit spectroscopic properties very similar to those of the single bifluorene system: nearly the same lowest-energy absorption bands around $330 \mathrm{~nm}$, similar fluorescence spectra in either solutions or in thin films, and similarly high fluorescence quantum yields of UV emission in thin films (Table 1, and Figures S-2 and S-3 in Supporting Information). These transitions agree with characteristics of the lowest $\pi-\pi^{*}$ transition of the bifluorene chromophore and appear consistent with the viewpoint that the tetrahedral spiro-center serves as an effective spacer blocking one branch from altering the electronic transition of the other branch. These results clearly indicate that both the peripheral aryl substituents and spiro-configuration are effective in suppressing quenching due to intermolecular interactions and in preserving the highly efficient UV emission of the bifluorene backbone, yet the spiro-configuration provides even more enhanced thermal and morphological stability. To explore possilbe applications of the large-gap bifluorenes in electrophosphorescence, phosphorescence of bifluorenes in thin films were also detected (at $77 \mathrm{~K}$ ). As an example, Figure 1 compares the fluorescence (room temperature) and

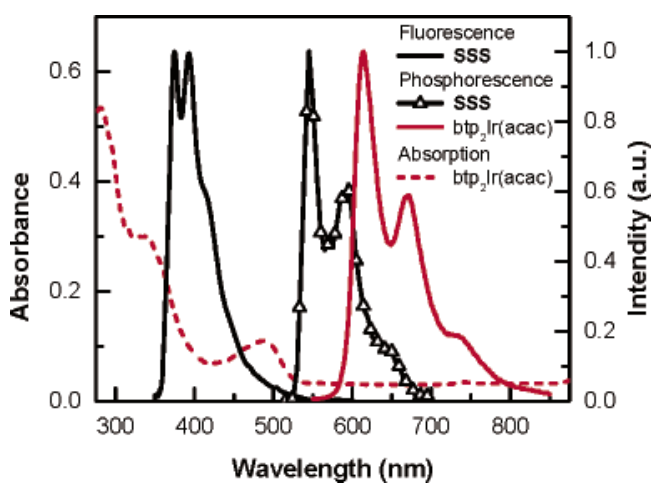

Figure 1. Fluorescence (room temperature) and phosphorescence $(77 \mathrm{~K})$ spectra of SSS in thin films and the absorption and emission spectra of the red triplet emitter $\mathrm{Btp}_{2} \mathrm{Ir}(\mathrm{acac})$ in $\mathrm{CHCl}_{3}$ slution.

phosphorescence ( $77 \mathrm{~K}$ ) spectra of SSS in thin films. A large red shift from 374 to $545 \mathrm{~nm}$ occurs between the emission peaks of fluorescence and phosphorescence, corresponding to an exchange energy of $\sim 1 \mathrm{eV}$ between the singlet state and the triplet state of bifluorenes. As shown in Figure 2 and in Table 1, all the bifluorenes show triplet energies in the green range of $\sim 2.3 \mathrm{eV}$ (defined as the highest-energy peak of the phosphorescence spectrum), indicating that they may be used as efficient hosts for yellow to red phosphorescent emitters.

These spiro-configured bifluorenes have been subjected to electroluminescent (EL) studies. The device structure used is ITO/PEDT:PSS(300 $\AA$ )/TCTA (400 $\AA$ )/SSS (Device A) or TST (Device B) $(300 \AA) / \mathrm{TPBI}(300 \AA) / \mathrm{LiF}(5 \AA) / \mathrm{Al}$. The conducting polymer polyetheylene dioxythiophene:polystrene sulfonate (PEDT:PSS) was used as the hole injection layer, $4,4^{\prime}, 4^{\prime \prime}$-tri( $N$-carbazolyl)triphenylamine (TCTA) as the holetransport layer, $2,2^{\prime}, 2^{\prime}-(1,3,5$-benzenetriyl)tris[1-phenyl-1H-

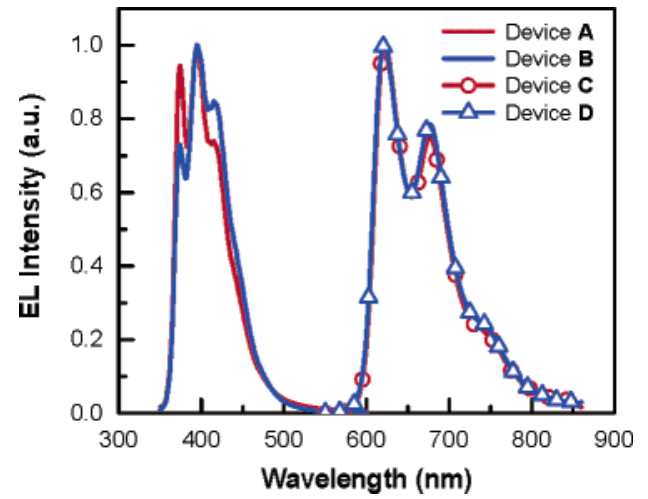

Figure 2. EL spectra of UV devices A (SSS) and B (TST) and red phosphorescent devices $\mathbf{C}\left(\mathrm{Btp}_{2} \operatorname{Ir}(\mathrm{acac}): \mathbf{S S S}\right)$ and $\mathbf{D}\left(\mathrm{Btp}_{2} \mathrm{Ir}-\right.$ (acac):TST).

benzimidazole] (TPBI) as the electron-transport layer, and $5 \AA \mathrm{LiF}$ as the electron-injection layer. Both devices exhibit UV EL similar to PL spectra of SSS and TST (Figure 2), indicating emission purely from SSS and TST. The SSS device exhibits the most prominent emission below $400 \mathrm{~nm}$ with two distinct EL peaks at $\sim 373$ and $\sim 393 \mathrm{~nm}$. These UV-emitting devices exhibit high EL quantum efficiencies (2.6\% for device A, $3.1 \%$ for device B; Figure S-4, Supporting Information), low turn-on voltage of $\sim 3 \mathrm{~V}$ and high EL brightnesses $\left(\sim 4020 \mathrm{~cd} / \mathrm{m}^{2}\right.$ at $\sim 13.5 \mathrm{~V}$ for device A, $\sim 3600 \mathrm{~cd} / \mathrm{m}^{2}$ at $\sim 12 \mathrm{~V}$ for device $\mathbf{B}$; Figure $\mathrm{S}-5$, Supporting Information).

SSS and TST have also been investigated as the host materials for red phosphorescent devices with the device structure of ITO/PEDT:PSS (300 $) /$ TCTA $(300 \AA) / 8$ wt \% $\mathrm{Btp}_{2} \operatorname{Ir}(\mathrm{acac})$ doped in SSS (Device C) or TST (Device D) $(300 \AA) / \mathrm{BCP}(100 \AA) / \mathrm{Alq}_{3}(600 \AA) / \mathrm{LiF}(5 \AA) / \mathrm{Al}$. The emitting layer (EML) consists of the large energy-gap SSS (or TST) doped with 8 wt $\%$ of the common red phosphor bis(2-(2'-benzo[4,5- $\alpha]$ thienyl) pyridinato- $\left.N, \mathrm{C}^{3^{\prime}}\right) \quad\left(\mathrm{Btp}_{2} \mathrm{Ir}-\right.$ (acac)). ${ }^{7} \mathrm{~A}$ thin layer of 2,9-dimethyl-4,7-diphenyl-1,10phenanthroline (BCP) was inserted between the EML and the electron-transport tris(8-hydroxyquinoline)aluminum as the hole-blocking and exciton-blocking layer to provide exciton and carrier confinement.

As shown in Figure 1, the triplet energy of SSS and TST $(\sim 2.28 \mathrm{eV})$ is higher than that of $\operatorname{Btp}_{2} \operatorname{Ir}(\mathrm{acac})(\sim 2.0 \mathrm{eV})$, ensuring that the triplet energy transfer from SSS (or TST) to $B t p_{2} \operatorname{Ir}(\mathrm{acac})$ is exothermic and the transferred triplet excitons are well confined on $B \operatorname{tp}_{2} \operatorname{Ir}(\mathrm{acac}){ }^{8}$ As a result, both electrophosphorescence devices exhibit pure red EL from $\mathrm{Btp}_{2} \operatorname{Ir}$ (acac) (Figure 2), and no emission from SSS (or TST) is observed, indicative of complete energy transfer from SSS (or TST) to $B t_{2} \operatorname{Ir}(\mathrm{acac})$. High brightness of $\sim 4060$ and $\sim 4330 \mathrm{~cd} / \mathrm{m}^{2}$ are obtained for device $\mathbf{C}$ and device $\mathbf{D}$,

(7) Adachi, C.; Baldo, M. A.; Forrest, S. R.; Lamansky, S.; Thompson, M. E.; Kwong, R. C. Appl. Phys. Lett. 2001, 78, 1622.

(8) Kawamura, Y.; Goushi, K.; Brooks, J.; Brown, J. J.; Sasabe, H.; Adachi, C. Appl. Phys. Lett. 2005, 86, 071104. 


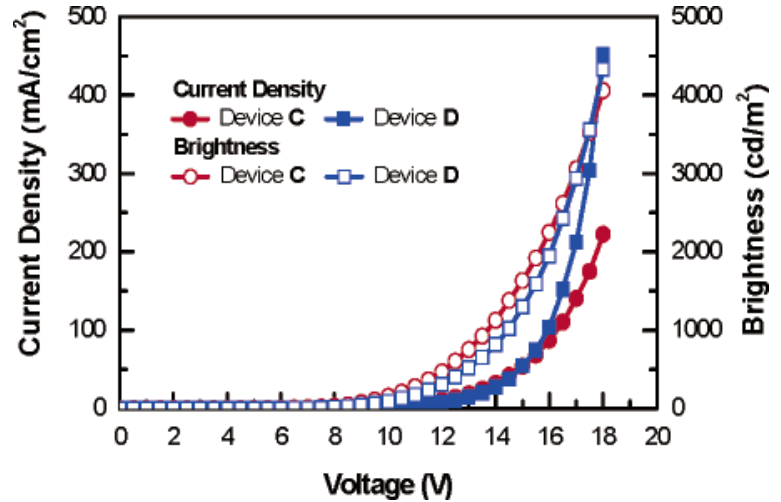

Figure 3. Device $I-V$ - $L$ characteristics of ITO/PEDT:PSS (300 $\AA$ )/ TCTA $(300 \AA) / \operatorname{Btp}_{2} \operatorname{Ir}(\mathrm{acac}) 8 \%$ doped in SSS or TST $(300 \AA) /$ BCP $(100 \AA) / \mathrm{Alq}_{3}(600 \AA) / \mathrm{LiF}(5 \AA) / \mathrm{Al}$.

respectively (Figure 3). The present devices possess rather low turn-on voltages of $\sim 2.5-3.0 \mathrm{~V}$, indicating effective carrier injection into the doped emitting layer from adjacent hole-transporting and hole-blocking layers. The maximal EL quantum efficiencies is $8.6 \%$ (at $0.3 \mathrm{~mA} / \mathrm{cm}^{2}$ ) for device $\mathbf{C}$ and $\sim 10 \%$ (at $0.07 \mathrm{~mA} / \mathrm{cm}^{2}$ ) for device $\mathbf{D}$ (Figure 4). Such efficiency is probably still limited by the emission quantum yield of $\operatorname{Btp} 2 \operatorname{Ir}(\mathrm{acac})$, which is only $\sim 50 \%$ as measured.

Both devices exhibit maximal power efficiency of $\sim 4.0$ $\mathrm{lm} / \mathrm{W}$. The devices show a gradual decrease in EL quantum efficiency with current, which is often observed in phosphorescent OLEDs and is usually attributed to triplet-triplet annihilation. ${ }^{9}$ Nevertheless, at a practical brightness of 100 $\mathrm{cd} / \mathrm{m}^{2}$ (at $\sim 2 \mathrm{~mA} / \mathrm{cm}^{2}$ ), the device efficiency remains above $8.4 \%$, which is still substantially higher than that of fluorescent red OLEDs $(3-5 \%)$ used in current OLED displays. When compared with red phosphorescent OLEDs using the same triplet emitter in a traditional CBP $\left(4,4^{\prime}\right.$-bis(9-carbazolyl)-2,2'-biphenyl) host, the devices using SSS (or TST) as the host show substantially improved performance. The maximum EL quantum efficiency (10\%) obtained here is substantially higher than that obtained with the CBP host

(9) Baldo, M. A.; Adachi, C.; Forrest, S. R. Phys. Rev. B 2000, 62, 10967.

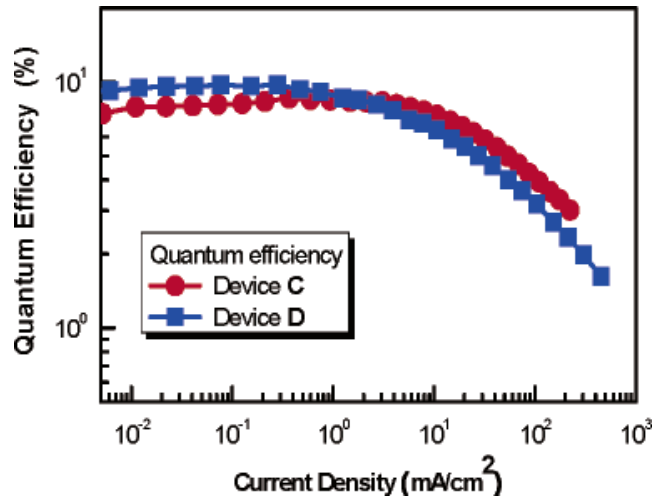

Figure 4. EL quantum efficiencies versus current density for devices $\mathrm{C}$ and $\mathrm{D}$.

$(\sim 7 \%){ }^{7}$ In addition, the SSS (or TST) device also show a less efficiency roll-off at high current densities.

In summary, novel large-gap spiro-configured bi(9,9diaryfluorene)s that can be used as efficient UV emitters in UV OLEDs and as effective host materials for electrophosphorescent devices have been successfully synthesized and characterized. In comparison with the bi(9,9-diaryfluorene) model compounds, these spiro-configured compounds exhibit enhanced morphological and thermal stability and more distinguished UV emission. Efficient UV OLEDs and red phosphorescent devices using these compounds have been demonstrated. Particularly, the electrophosphorescence results here represent the first example of using a pure hydrocarbon small molecule as an efficient host for red electrophosphorescence devices.

Acknowledgment. This work was financially supported by the National Science Council of Taiwan.

Supporting Information Available: Detail experimental procedure and spectroscopic characterization of new compounds, cyclic voltammograms, absorption and emission spectra of compounds in solutions and in thin films, characteristics of UV OLEDs. This material is available free of charge via the Internet at http://pubs.acs.org.

OL051865Q 